\title{
UNCONSCIOUS BIAS
} LIMITS WOMEN'SCAREERS

Among Japan's research population, men outnumber women six to one. Two leading female scientists in Japan speak about their experiences.

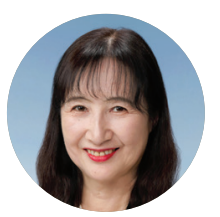

Q \& A MIYOKO WATANABE

Watanabe is deputy executive director of the Japan Science and Technology Agency (JST) and director of JST's Office for Diversity and Inclusion.

\section{Q: What was it like starting out as a young researcher?}

I was hired as the first female researcher at Toshiba in 1979, after completing my undergraduate degree in physics at Tokyo University of Science. My managers just expected me to be present. This gave me the freedom to do basic research in semiconductor physics. I wrote a lot of papers, included in top journals such as Physical Review Letters, and was recognized as a good researcher. It was an unconventional route to a $\mathrm{PhD}$, which I received in 1986.

Male researchers at the company did not enjoy as much freedom, as they were expected to do more applied research. But they had access to factories, which I didn't have as a woman, and were given more opportunities to learn about Toshiba's business.

Q: Women represent only about $16 \%$ of the researcher population in Japan today. Why is the ratio so low?

Unconscious biases about a woman's research lifespan are widespread. Many men believe that women will leave the workforce after having children.

The distribution of funding is also skewed towards men. Faced with poor odds, women often refrain from applying for funding. Look, for example, at two of JST's strategic basic research programmes: Core Research for Evolutional Science and Technology (CREST) and Precursory Research for Embryonic Science

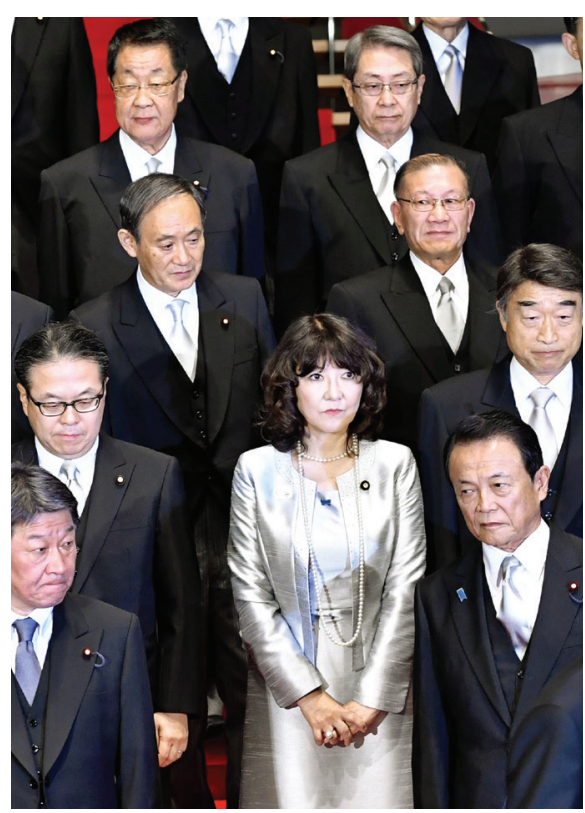

Satsuki Katayama, the only woman among Japan's 19 Cabinet ministers.

and Technology (PRESTO). In 2018, women made up 5.2\% of CREST applicants and 5.4\% of those who received funding. They made up $8.8 \%$ of PRESTO applicants, and $10.3 \%$ of those funded. Women are also burdened by the need to join the many committees created to promote gender equality.

Japanese cultural expectations also contribute to the gender inequality in science. It is considered a virtue for women to be modest and humble. Those who speak out or attack other people are thought to be undesirable.

\section{Q: Why is it important to bring more women into science?}

Diversity is crucial for increasing the quality of research. A 2018 analysis showed that the economic value of patents in Japan by mixed gender teams was $154 \%$ higher than that of allmale teams.
We expect diversity to confer similar advantages in other areas of science and innovation. But many senior male researchers argue that research quality is independent of diversity. They see gender equality as a human right, but do not recognize its value beyond that. The younger generation is more open-minded. Of course, some senior men, especially those with international exposure, would like to see more female leaders in Japan.

With growing investment in artificial intelligence, we especially need to increase the female presence in the information and computer sciences. Our future will be governed by AI, but the field is dominated by men.

Another major concern in Japan is the lack of integration between the humanities, social sciences, natural sciences, and engineering. Female researchers could help bridge these divides through collaboration. Women are more friendly with people in different fields, and more talkative.

\section{Q: How successful have government efforts been in improving female employment?}

Not very successful. The percentage of women is increasing yearly, but change happens slowly in Japan. In the US and Europe, people in leadership positions can make independent decisions. In Japan, however, decisions are made through a lengthier process of consultation and consensus.

The government could start by looking inward: the female ratio in government departments is especially low. Of the 19 ministers in the current Cabinet, only one is a woman.

\section{Q: What is JST doing to improve the situation for female scientists?}

In May 2017, JST hosted the tenth Gender Summit, which brought together 600 people to discuss science and gender. A follow-up symposium was held in June 2018.

We also organise an annual symposium specifically for mothers of high school students to encourage more girls to study science and engineering. Many mothers worry that their daughters will not succeed in these fields. But society is changing. Large companies like Toyota would like to hire more women, and have even set up foundations to offer grants and scholarships for them.

JST would also like to increase the representation of women among grant applicants and evaluators. As a result of JST's promotion activities, the number of female evaluators has increased from 124 in 2012 to 163 in 2016. Male evaluators have decreased from 725 to 445 during that period.

Another proposal is to create a funding stream solely for women. This is a sensitive point, though, as many men see it as discriminatory. Our funding is governed by the Ministry of Education, Culture, Sports, Science and Technology. It takes a long time to reach an agreement on this matter with people at the ministry because it is a new proposal. 


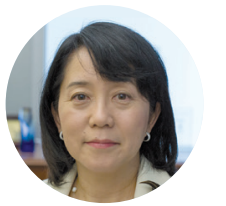

Takahashi is project leader of the Laboratory for Retinal Regeneration at the RIKEN Center for Biosystems Dynamics Research in Kobe.

\section{Q: What were your early experiences} as a clinician and researcher?

I was lucky to have chosen ophthalmology, a field that is roughly $50 \%$ female. From early on, I felt that women were treated equally to men.

But the working environment for medical practitioners at the university hospital was terrible. We had to work until 10 or 11 every evening, sometimes even through the night. That was a very tough period for me, because I had two small children to take care of. My husband was also a clinician, a brain surgeon, and his hours were even longer than mine. So although he wanted to help with raising the kids, he could not, leaving it entirely to me.

Things were better for me when I left the clinic for basic research. Research offers a good environment for women. You might need to work long hours, but you are in control of how you manage your time. I never experienced any prejudice from my bosses or mentors.

\section{Q: What is your reaction to the revela- tions that several Japanese medical schools discriminated against female applicants?}

It did not surprise me. Japan has a limited number of doctors and the working environment in hospitals is very harsh. Female clinicians often quit to take care of their children. If hospitals were to hire too many women, their operation would be disrupted. Many female doctors don't blame the medical schools. They understand the situation.

I do not see these incidents as representing prejudice against women, but rather a problem of the working environment for doctors in Japan's medical system.

\section{Q: Why are female researchers so underrepresented in Japan?}

Traditionally, very few women worked in Japan. Thirty years ago, few Japanese men participated in raising kids. You would never see fathers bring their kids to nursery school. Nowadays, many men do. But some mothers-in-law still believe that wives should not work.

At school, women are also taught to be assistants, not bosses. This makes them reluctant to take leadership positions. At our institute, only a few women apply for principal investigator positions. I myself did not want to take on the role of group leader. I felt compelled to be one, but if someone could take my place, I would happily give it up.

\section{OUT OF THE PICTURE}

Women are excluded from many aspects of academic life in Japan. However, men and women have differing opinions on the extent to which female researchers are discriminated against, according to a 2017 survey of more than 1,200 researchers.

Researchers 2018

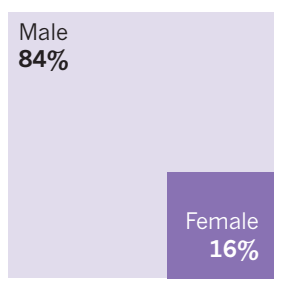
JST evaluators 2016

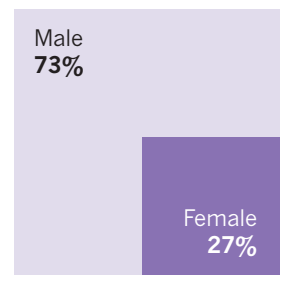

Q. Do you feel that women are disadvantaged when applying for public funding?

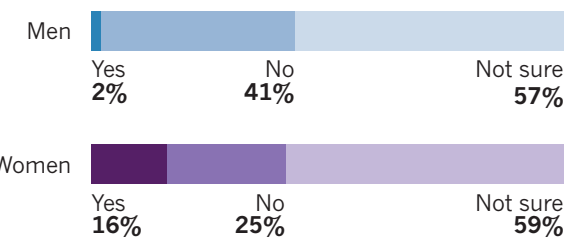

Q: Why did you decide to spearhead research into retinal regeneration?

In 1995, while working as a postdoctoral researcher at the Salk Institute for Biological Studies in the United States, I was introduced to the concept of neural stem cells. As an ophthalmologist with a rare knowledge of stem cells, I was among the few people globally who could work on developing such treatments for eye disease. I felt obliged to lead the initiative.

\section{AT SCHOOL, WOMEN ARE TAUGHT TO BE ASSISTANTS, NOT BOSSES, WHICH MAKES THEM RELUCTANT TO TAKE LEADERSHIP POSITIONS.}

\section{Q: What has helped you succeed in your research?}

I chose the right issue to solve and the right method to solve it.

I also benefited from being a woman. My project involves translational research, and combines many skills, fields and techniques. I see myself as more of a team player than a top researcher. Instead of ordering people to do things, I ask for their assistance. Such collaborative projects are well suited for women. People are especially keen to help women.

\section{Q: Why is it important to increase the presence of women in science?}

Japanese society has an equal number of
Applicants to CREST \& PRESTO grants 2018

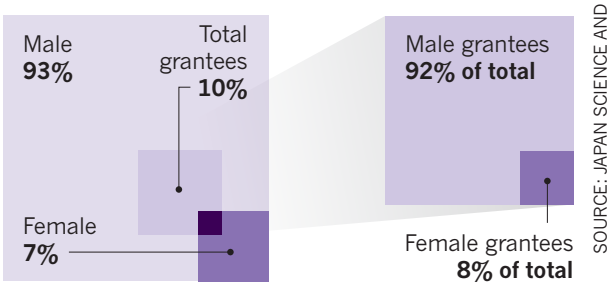

Q. Should there be a female-only track for applying for public funding?

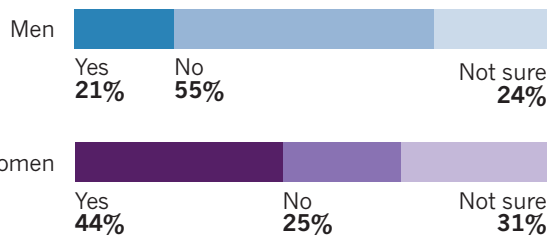

talented men and women, so we should utilize that talent to make progress.

\section{Q: Tell us about your experiences engaging with the private sector.}

Many prejudices prevail. I am a founder of two start-ups and a board member of a large healthcare company. In this capacity, I have noticed an absence of women in industry. At a seminar of some 200 people, one might find two or three female board members. It is a pity that the business sector does not utilize women's talents.

\section{Q: How do you plan to take your stem cell research forward?}

My team was the first to use induced pluripotent stem (iPS) cells in a clinical study. We transplanted retinal pigment epithelial cells derived from a patient or an anonymous donor. We will continue to improve these treatments.

In parallel, we plan to develop a protocol for transplanting another type of cell known as photoreceptor cells, which are neurons involved in perceiving light, derived from iPS cells. The research should begin this year, with surgery to start a year later.

This is essential research. Retinal diseases involve the central nervous system, which means that cell therapy is the only form of treatment available to patients.

\section{Q: What advice would you give to young female researchers in Japan?}

The situation in Japan is changing, with many opportunities for women. Young female researchers should believe that they can become leaders and top principal investigators. They should think of themselves as equal to men. SMRITI MALLAPATY a 